\title{
O papel dos amuletos em cemitérios de não elite no Antigo Egito
}

ARROYO. V. O papel dos amuletos em cemitérios de não elite no Antigo Egito. R. Museu Arq. Etn., 35: 69-78, 2020.

Resumo: Este artigo busca expandir a noção sobre amuletos no Antigo Egito por meio da discussão sobre a contextualização desses objetos em cemitérios de não elite. Para tanto, demonstramos a variabilidade contextual e a diversidade social caracterizada por diferentes práticas, apropriações e ressignificações dessa cultura material em enterramentos. A intenção é questionar interpretações generalizantes dos amuletos concebidas a partir de fontes textuais e iconográficas acessíveis apenas para a elite. Através da análise contextual de dados sobre amuletos encontrados em três sítios - Gurob, Matmar e Lahun - pretendemos refletir sobre as diferentes práticas e crenças em relação a não elite.

Palavras-chave: Amuletos; Antigo Egito; Não elite; Práticas funerárias.

\section{Introdução}

U $m$ dos artefatos mais presentes na sociedade do Antigo Egito são os amuletos, objetos pessoais que por sua forma, material e cor, acreditava-se que dotavam seu usuário de poderes mágicos ou proteção (Andrews 1994: 6). Eles são encontrados em contextos funerários, domésticos (Stevens 2006) e votivos (Pinch 1993). O uso de amuletos em enterramentos de pessoas menos influentes da sociedade egípcia antiga é atestado por diversas escavações (e. g. Brunton 1920; Brunton \& Engelbach 1927; Brunton 1948; Kemp et al. 2013), porém, os estudos sobre esses objetos estão majoritariamente concentrados em tumbas que apresentam uma grande variedade e volume de cultura material, ou seja, tumbas de faraós, rainhas e pessoas da elite.

É o caso de Tayesmutengebtiu, por exemplo, uma cantora do Templo de Amon e, portanto,

* Graduada em História pela FFLCH-USP e mestranda no Museu de Arqueologia e Etnologia da Universidade de São Paulo. <victoria.arroyo@live.com> integrante da elite religiosa da sociedade egípcia do começo da XXII Dinastia (ca. 900 BCE). Na tomografia de sua múmia foi possivel identificar diversos amuletos posicionados em vários locais de seu corpo entre as bandagens (Taylor, Antoine \& Vandenbeusch 2014: 69). Há também a presença de amuletos em múmias reais - a múmia de Tutankhamun, por exemplo, continha 143 amuletos e joias entre as bandagens de diversas partes do corpo (Ikram 2003: 97).

Segundo as fontes textuais, a materialidade era fundamental para que um amuleto pudesse exercer sua função. No caso dos amuletos funerários sua principal função era proteger o espírito do morto em sua passagem para o pós-vida e por isso eram colocados entre as bandagens das múmias (Ikram 2003: 95). Cada amuleto tinha uma função específica dependendo de sua forma, cor e material (Andrews 1994: 6). Como exemplo há o amuleto chamado de nó de Ísis (tit) (FIGURA 1) inspirado no nó feito em tecido que era usado por mulheres para conter o sangue menstrual. $\mathrm{O}$ amuleto era feito de cornalina ou jaspe, minerais de cor vermelha amarronzada, que 
aludem à cor do sangue e do sol simbolizando vitalidade e energia (Muñoz Pérez 2018: 70). Sua função era proteger a vida de seu usuário, uma vez que seu formato remete ao símbolo hieróglifo que representa a vida (Andrews 1994). O simbolismo da materialidade do objeto era de suma importância para a execução correta da função do amuleto, e ele só poderia ser ativado, ou seja, exercer sua função, após passar por um ritual pelo qual um sacerdote recitava os encantamentos necessários. No Livro dos Mortos constam instruções específicas sobre os elementos materiais que deveriam compor o amuleto nó de Ísis, assim como o encantamento a ser recitado:

\section{CAPÍTULO 156:}

Fórmula para o nó tjt de jaspe vermelho.

"Tu tens teu poder mágico, Ísis, tu tens tua magia, Ísis, o amuleto é a proteção desse grande deus, que reprime aquele que o está prejudicando." Palauras a dizer sobre um nó tjt de jaspe vermelho, tendo sido umedecido com a seiva da plantaankh-imy, suspenso por um (cordão em) fibra de sicômoro, e que foi colocada ao redor do pescoço desse abençoado, no dia do enterramento. Aquele para quem é recitado, o poder mágico de Îsis será a proteção de seu corpo, e Hórus, filho de Ísis, se alegrará dele quando o ver; o segredo de um caminho não existirá para ele, um (de seus) lados virados para o céu, o seu (outro) lado para a terra. Isso foi realmente eficaz. Não deixe ele ver nenhum homem! Sim, não há ninguém a seu lado! (Barguet 1967: 225).

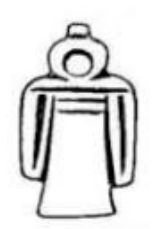

Fig. 1: Amuleto com forma do nó de Isis (tjt) em jaspe vermelho do sítio de Gurob.

Fonte: Brunton \& Engelbach (1927).

Fontes textuais, principalmente as provenientes de enterramentos de elite - como é o caso do Livro dos Mortos - eram acessíveis apenas para a camada letrada da população egípcia antiga, ou seja, a elite. Os textos, portanto, não nos permitem alcançar diretamente uma sociedade em todos os seus aspectos e variações (Kemp 1984). Esses amuletos eram restritos a uma pequena parte da população, logo, o conhecimento atual sobre eles é generalizado. A abordagem contextual da cultura material, então, é uma maneira adequada para interpretar as práticas e significados de amuletos em enterramentos da não elite.

Estudar o papel simbólico dos amuletos nessa parcela da sociedade, a não elite, é importante para entender como essas pessoas concebiam práticas religiosas e funerárias. Assim sendo, o objetivo deste artigo é discutir o papel simbólico dos amuletos funerários no contexto de enterramentos da não elite através de dados provenientes de três cemitérios e o que eles podem nos dizer sobre a concepção de pós-vida dessa camada da sociedade egípcia antiga a partir de uma abordagem contextual. Dessa forma, considerando as práticas e (re)significados que a não elite atribuía aos amuletos depositados como seu acompanhamento funerário, buscamos também expandir o conhecimento a respeito desse tema nas práticas funerárias do Antigo Egito.

Os cemitérios da não elite nos quais os dados a respeito dos amuletos foram coletados estão localizados nos sítios de Gurob, datado do Reino Novo (ca. 1550-1069 BCE), Matmar e Lahun, do Terceiro Período Intermediário (ca. 1069-664 BCE). Serão utilizadas as informações detalhadas nos relatórios de escavação desses sítios com o objetivo de construir um contexto simbólico específico para os amuletos. Como dados acerca da não elite são raros, esses sítios, ainda que explorados no início do século XX de maneira questionável à luz das práticas da arqueologia atual, fornecem informações fundamentais para os propósitos deste artigo. Além disso, em virtude de o destino em morte da maioria das pessoas no Antigo Egito ser pouco conhecido - por terem sido enterradas de maneiras pelas quais a arqueologia ainda não as localizou (Baines \& Lacovara 2002: 6) - as informações acerca da cultura material de cemitérios da não elite são bastante escassas e, portanto, escavações antigas não devem ser descartadas. 


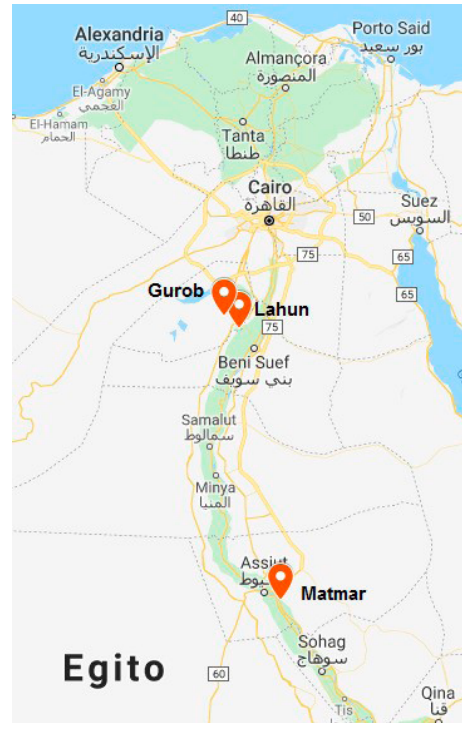

Fig. 2: Mapa do Egito com os sítios analisados. Fonte: Produção do autor. Gerado com Google Maps.

\begin{tabular}{ll}
\hline \multicolumn{2}{c}{ Cronologia do Antigo Egito } \\
\hline Período Pré-dinástico & c. $5300-3000 \mathrm{BCE}$ \\
Período Dinástico Inicial & c. $3000-2686 \mathrm{BCE}$ \\
Reino Antigo & $2686-2160 \mathrm{BCE}$ \\
Primeiro Período Intermediário & $2160-2055 \mathrm{BCE}$ \\
Reino Médio & $2055-1650 \mathrm{BCE}$ \\
Segundo Periodo Intermediário & $1650-1550 \mathrm{BCE}$ \\
Reino Novo & $1550-1069 \mathrm{BCE}$ \\
Terceiro Período Intermediário & $1069-664 \mathrm{BCE}$ \\
Época Tardia & $664-332 \mathrm{BCE}$ \\
Período Ptolomaico & $332-30 \mathrm{BCE}$ \\
Período Romano & $30 \mathrm{BCE}-\mathrm{ACE} 395$ \\
\hline
\end{tabular}

Tabela 1: Cronologia do Antigo Egito.

Fonte: Shaw (2000: 480-489).

\section{Amuletos em contextos funerários de não elite}

Como a documentação sobre o contexto cultural e religioso do Antigo Egito está majoritariamente ligada à elite e pessoas letradas que poderiam ter acesso a bens materiais e textos escritos em hieróglifos, ela exprime uma visão de mundo particular e restrita. A não elite não possuía acesso a essas fontes textuais e aos grupos que as detinham e, portanto, ao conhecimento compartilhado por eles. Ainda assim, por fazer parte dessa sociedade, a não elite tinha certo acesso à referência da cultura material e como ela era feita. Essa noção deveria ser estritamente visual e não conceitual, não compartilhando os mesmos significados simbólicos com a elite. Deste modo, embora possuíssem as mesmas formas e sendo feitos dos mesmos materiais, os objetos da não elite eram ressignificados, com conotações que atestam a diversidade cultural da sociedade egípcia antiga, uma vez que os significados da cultura material dependem do contexto em que se encontram.

Estudos acadêmicos mais recentes têm se concentrado na diversidade cultural a partir do contexto funerário da não elite (e. g. Humphreys 2010; Goulding 2013; Cahail 2014; Lemos 2015; Janulíková 2017) corroborando preocupações a respeito dessa pluralidade no Antigo Egito.

J. Richards concebeu um fenômeno na Egiptologia que ela chama de "tomb problem", definido como o interesse em tumbas ricamente providas de cultura material à custa de acessar a variedade de comportamentos funerários em cemitérios do Antigo Egito. Uma atitude que promove a falta de entendimento sobre mudanças nas práticas culturais, religiosas e funerárias dessa sociedade (Richards 2005: 49). Por sua vez, G. Pinch afirma que a concentração de estudos nas práticas da elite ignora as crenças de grande parte da população, assim como a variação regional das práticas funerárias. Ela argumenta que pessoas de classes mais baixas, por não terem acesso aos textos e imagens produzidas por escribas e artistas, estavam mais inclinadas a usar objetos simbolicamente para estabelecer o status e a identidade do morto, assim como para ajudar e facilitar a transição de corpo e espírito para o pós-vida (Pinch 2000: 443). Logo, as percepções das necessidades funerárias no Antigo Egito não eram unificadas socialmente, onde a perspectiva da elite é caracterizada através das fontes iconográficas e textuais, e, por isso, outros significados simbólicos e interpretações foram introduzidos na cultura material presente no conjunto funerário da maioria da população (Baines \& Lacovara 2002: 7-15).

Portanto, as práticas funerárias da não elite devem ser entendidas através da abordagem 
contextual dos dados arqueológicos provenientes desses tipos de enterramentos, sem recorrer ao panorama generalizante estabelecido mediante estudos sobre a elite. Por ser centrada no objeto, a análise contextual permite maior variabilidade cultural, uma vez que práticas devem ser comprovadas, e não assumidas previamente (Hodder 1987: 5). Dessa maneira, para apreendermos padrões de forma particularizada é necessária a análise dos dados arqueológicos a respeito da cultura material presentes em certo contexto (Hodder \& Hutson 1986: 5-6).

Analisando os enterramentos dos sítios de Gurob, Matmar e Lahun foi possivel estabelecer certos padrões a respeito dos contextos mortuários da não elite. Os enterramentos da não elite compreendem diversos tipos que variam de fossos funerários até túmulos de poço com paredes de tijolos, assim como frequentes reutilizações de tumbas de épocas anteriores. O corpo poderia ter sido enterrado diretamente na areia do deserto ou estar envolvido por esteiras de origem vegetal. Há alguns raros casos de caixões antropomórficos ou pintados. Alguns corpos de crianças estavam em jarros ou vasos cerâmicos. Não há sinais claros de mumificação, apenas em Matmar havia corpos com indícios de tentativas de preservação intencional, com a presença de tecidos dentro da pélvis.

Entre os acompanhamentos funerários havia um grande volume de objetos associados à esfera cotidiana, como anéis, brincos, cerâmicas, contas, potes de kohl, colheres para cosméticos e instrumentos musicais; assim como objetos exclusivamente feitos para serem depositados com o morto, como escaravelhos e shabtis. Alguns enterramentos continham uma grande quantidade de acompanhamentos funerários, mas a variedade era reduzida com uma excessiva parcela dos mesmos tipos de objetos. Logo, os dados demonstram que a não elite não era um grupo social uniforme, com a presença de variações nas práticas funerárias entre os sítios que podem ser consequência da diferença de localidade e período.

Mesmo assim, podemos identificar padrões em enterramentos da não elite, como a falta de mumificação, ausência de textos e iconografia, além da pouca variedade de cultura material depositada com o morto, principalmente de objetos estritamente funerários. Verifica-se a inexistência de tentativas de categorização de grupos sociais no Antigo Egito a partir de uma abordagem contextual baseada na cultura material. Por estar mais preocupada com arte e fontes textuais, muitas vezes presentes em tumbas de elite, do que com a teoria social, a Egiptologia trata de grupos sociais sem uma compreensão sociológica do tema, por isso a maior fonte de informação sobre estratificação social no Antigo Egito são dados de escavações (Grajetzki 2010: 181-3).

R. Lemos, que aproximou a teoria social da abordagem contextual de dados em três cemitérios, afirma que a não elite interagia limitadamente com outros grupos sociais por não ter acesso a bens materiais e, portanto, não poderiam negociar sua posição na sociedade (Lemos 2017: 124). Ele ainda afirma que diferentes grupos sociais poderiam adotar suas próprias formas de significar o mundo (Lemos 2018: 25). Logo, o significado de um objeto dependerá de suas práticas e usos em um contexto particular (Hodder 1992: 12). Os objetos tanto da esfera cotidiana, que poderiam ter sido usados em vida, quanto os especificamente funerários eram reapropriados e ressignificados nesses enterramentos por pessoas que não tinham contato com o campo ideológico da elite e que podem ser interpretados a partir da busca por informações dadas em contexto.

\section{Análise dos dados}

A seguir apresentaremos os dados dos amuletos provenientes dos enterramentos da não elite de Gurob, Matmar e Lahun, a fim de estabelecermos o contexto das práticas em que foram utilizados e interpretarmos seu significado, uma vez que o significado é atribuído através de práticas (Bussmann 2015: 9). Os dados são originários dos relatórios de escavação dos sítios (Brunton 1920; Petrie, Brunton \& Murray 1923; Brunton \& Engelbach 1927; Brunton 1948) e de um catálogo feito por D. Aston no qual o autor realiza uma revisão das informações de todos os enterramentos do Terceiro Período Intermediário (Aston 2009). 
Quantidade de amuletos

\begin{tabular}{lcccc}
\hline \multicolumn{1}{c}{ Sítio } & $\begin{array}{c}\text { Total de } \\
\text { enterramentos }\end{array}$ & $\begin{array}{c}\text { Enterramentos } \\
\text { com amuletos }\end{array}$ & $\begin{array}{c}\text { Porcentagem de enterramentos } \\
\text { com amuletos }\end{array}$ & $\begin{array}{c}\text { Quantidade total } \\
\text { de amuletos }\end{array}$ \\
\hline Gurob & 313 & 42 & $13 \%$ & 149 \\
Matmar & 276 & 125 & $45 \%$ & 309 \\
Lahun & 71 & 45 & $63 \%$ & 313 \\
\hline
\end{tabular}

Tabela 2: Distribuição de amuletos nos enterramentos dos sítios.

Em termos de quantidade, Matmar e Lahun apresentam uma grande quantidade de enterramentos com a presença de amuletos, sendo ambos do Terceiro Período Intermediário, enquanto o sítio de Gurob, provavelmente por seus enterramentos terem sido mais perturbados e saqueados, compreende apenas $13 \%$ de sepultamentos com amuletos. Em relação à quantidade total de amuletos, verificamos que Lahun, com menos enterramentos, contém o maior número de amuletos, uma ampla diferença para Gurob.

Tipos de amuletos

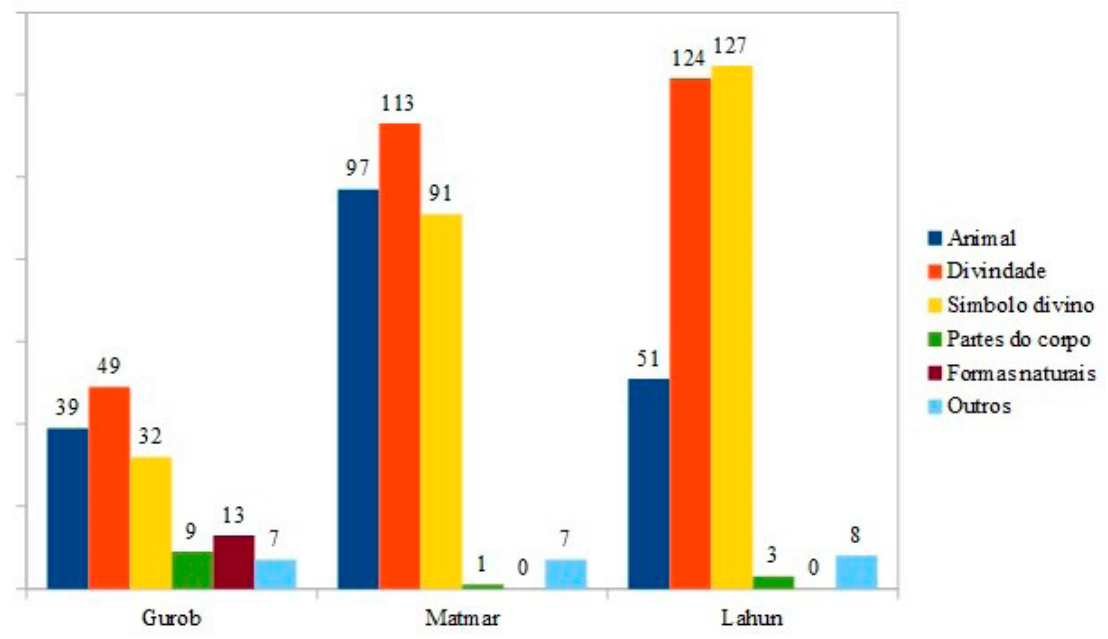

Fig. 3: Quantidade de tipos de amuletos em cada sítio.

Os tipos de amuletos representados através de suas formas podem ser divididos em: animais, divindades, símbolos divinos, partes do corpo, formas naturais (como flores e plantas) e outros. Este último compreendendo formas de amuletos que não se encaixam nas outras, como vasos, sítulas, liras e mesas de oferenda, assim como formas que não puderam ser identificadas.
Verificamos que nos três sítios a proporção é bastante equilibrada, com um maior volume de amuletos representando divindades, seguido por animais e símbolos divinos. No entanto, em Lahun há uma pequena parcela a mais de símbolos divinos do que divindades e animais. Logo, esses três tipos são os mais predominantes e apesar da diferença na quantidade de amuletos dos três sítios é interessante notar o equilíbrio na quantidade. 
O papel dos amuletos em cemitérios de não elite no Antigo Egito

R. Museu Arq. Etn., 35: 69-78, 2020.

Predominância e recorrência de certas formas por sexo e idade

\begin{tabular}{lccc}
\hline \multicolumn{1}{c}{ Forma/Sítio } & Gurob & Matmar & Lahun \\
\hline Wedjat & $\mathrm{X}$ & $\mathrm{X}$ & $\mathrm{X}$ \\
Taweret & $\mathrm{X}$ & $\mathrm{X}$ & \\
Sekhmet & & $\mathrm{X}$ & $\mathrm{X}$ \\
Bes & $\mathrm{X}$ & $\mathrm{X}$ & $\mathrm{X}$ \\
Gato & $\mathrm{X}$ & $\mathrm{X}$ & $\mathrm{X}$ \\
\hline
\end{tabular}

Tabela 3: Formas predominantes e recorrentes em enterramentos do sexo feminino.

\begin{tabular}{lccc}
\hline \multicolumn{1}{c}{ Forma/Sítio } & Gurob & Matmar & Lahun \\
\hline Wedjat & $\mathrm{X}$ & $\mathrm{X}$ & $\mathrm{X}$ \\
Bes & & & $\mathrm{X}$ \\
Sekhmet & & $\mathrm{X}$ & \\
\hline
\end{tabular}

Tabela 4: Formas predominantes e recorrentes em enterramentos do sexo masculino.

\begin{tabular}{lccc}
\hline \multicolumn{1}{c}{ Forma/Sítio } & Gurob & Matmar & Lahun \\
\hline Wedjat & $\mathrm{X}$ & $\mathrm{X}$ & $\mathrm{X}$ \\
Bes & $\mathrm{X}$ & $\mathrm{X}$ & $\mathrm{X}$ \\
\hline
\end{tabular}

Tabela 5: Formas predominantes e recorrentes em enterramentos infantis.

Os amuletos presentes nos enterramentos do sexo feminino em cada sítio expõem a predominância e recorrência de certas formas como o símbolo divino wedjat, também conhecido como olho de Hórus, da deusa Sekhmet, do deus Bes e de gatos. Com o sexo masculino foram depositados amuletos em forma de wedjat - única comum em todos os sítios -, da deusa Sekhmet e do deus Bes, tal como nos enterramentos de indivíduos do sexo feminino, que também aparece com crianças e é, desta maneira, recorrente nas três categoriais de enterramentos junto com o wedjat.

\begin{tabular}{lccc}
\hline Sexo e idade/Sítio & Gurob & Matmar & Lahun \\
\hline Sexo feminino & 29 & 64 & 16 \\
Sexo masculino & 5 & 16 & 6 \\
Infantil & 79 & 226 & 7 \\
\hline
\end{tabular}

Tabela 6: Quantidade total de amuletos em enterramentos por sexo e idade em cada sítio.
Em relação à quantidade de amuletos por sexo e idade, os três cemitérios apresentam a mesma conclusão em enterramentos que contém remanescentes humanos que puderam ser identificados: indivíduos do sexo feminino e crianças estavam mais propensas a serem enterradas com amuletos, enquanto o sexo masculino poderia ser enterrado com amuletos, mas não foi possível verificar essa ocorrência como padrão.

É importante notar que a maioria dos enterramentos em Lahun não contém informações sobre o sexo ou idade dos remanescentes humanos. Isso pode ser explicado pelo fato de que como os corpos da não elite não eram mumificados intencionalmente e furtos na antiguidade e nos tempos modernos eram comuns, muitos corpos podem ter sido danificados impossibilitando a identificação do sexo e idade através dos ossos e dentes. Devido aos dados terem sido retirados de relatórios de escavações antigos, devemos atentar para a realidade de que as análises osteológicas de remanescentes humanos com o objetivo de determinar sexo e idade ainda não haviam se tornado um campo de estudo formal, por isso os dados desses cemitérios devem ser considerados com cautela.

Posição dos amuletos

\begin{tabular}{ccc}
\hline Gurob & Matmar & Lahun \\
\hline Pescoço & Pescoço & Pescoço \\
Pulsos & Pulsos & Pulsos \\
Solto no & Solto no & \\
enterramento & enterramento & \\
Pés & \\
Tornozelos & \\
Ao lado do corpo & Cotovelos \\
& Ao lado da cabeça & \\
& Braços \\
& Cabeça \\
& Peito \\
& Em cima do caixão \\
& Em uma cesta \\
\hline
\end{tabular}

Tabela 7: Posição onde os amuletos foram encontrados em cada sítio. 
O posicionamento no qual os amuletos foram encontrados nem sempre reflete a localização em que foram depositados uma vez que enterramentos podem ter sido perturbados, principalmente no sítio de Gurob, que foi bastante saqueado. Esse deve ser o caso dos amuletos que foram encontrados soltos nos enterramentos. Mesmo assim, verificamos nos três sítios que os amuletos estavam posicionados, em sua maioria, no pescoço e nos pulsos dos remanescentes humanos. Em Matmar, os amuletos estavam em outras partes do corpo, assim como há a presença de um conjunto de amuletos dentro uma cesta no enterramento.

\section{Discussão}

A quantidade de amuletos é desigual nos três sítios, o que nos mostra que o uso de amuletos não era uniforme entre localidades e períodos, mesmo levando em consideração as perturbações e saques que podem ter ocorrido. Isso atesta uma variabilidade cultural e que os amuletos não eram objetos centrais para serem depositados como acompanhamentos funerários. Essa diversidade cultural também é atestada pela maior associação de amuletos em enterramentos de indivíduos do sexo feminino e crianças, possivelmente em função das crianças serem vistas como mais vulneráveis às doenças, assim como as mulheres que tinham de sobreviver aos perigos do parto e possuíam maior necessidade da proteção do corpo através dos amuletos. Os amuletos, então, poderiam ser ressignificados na morte após terem sido utilizados em vida.

Os tipos de amuletos mais presentes nos três sítios, em quantidades bastante equilibradas são os que representam divindades, símbolos divinos e animais. Os amuletos mais presentes nos três sítios e em proporção equilibrada são aqueles que ilustram divindades, assim como os símbolos e animais que as representam. Desses dois tipos, os amuletos mais frequentes nos enterramentos são wedjat, gato, porca e peixe. Wedjat, ou olho de Hórus, estava associado a esse deus e representava a ordem divina, assim como os gatos, associados à deusa Bastet e ao deus Ra. A deusa do céu Nut poderia ser representada como uma porca, e o peixe, por ser um animal constantemente presente na vida cotidiana, foi vinculado à deusa Hatmehyt (Pinch 2002). Dentre as divindades, Bes, Taweret e Sekhmet tem destaque nos enterramentos infantis e do sexo feminino. $\mathrm{O}$ deus Bes e a deusa Taweret estavam ligados à proteção de mulheres e crianças especificamente (Stevens 2006: 33), enquanto a deusa felina Sekhmet estava associada ao culto solar e a realeza, mas era cultuada em santuários pequenos, e talvez públicos, durante o Reino Novo (Stevens 2006: 38). Amuletos com as formas de Bes e Taweret foram recuperados em grande quantidade na cidade de Amarna, atestando seu uso na esfera cotidiana e a necessidade de proteção em vida, assim como na morte.

A posição em que os amuletos foram encontrados também corrobora sua função protetiva. A partir das informações que foram coletadas nos relatórios de escavação, a ampla maioria dos amuletos foi encontrada no corpo. Nos três sítios, o pescoço e pulsos eram os lugares mais comuns para a colocação de amuletos, provavelmente por estarem associados a colares e braceletes que poderiam incluir outros pingentes e vários tipos de contas. Contudo, em Matmar verificamos a presença de amuletos em outras partes do corpo. Uma vez que os enterramentos desse sítio eram os menos perturbados, há a maior possibilidade de serem a posição original em que esses amuletos foram colocados no corpo do morto antes de ser sepultado, verificando a importância de estarem em contato com a pessoa com quem eram depositados.

Como a cultura material e seu significado no Antigo Egito são explicados por meio de referências a textos, como os funerários, e imagens encontradas em estátuas e tumbas reais, há sempre o perigo de recorrermos à essas fontes quando interpretamos amuletos em contextos da não elite. Entre os amuletos analisados há apenas três exemplares de um amuleto com a forma do nó de Îsis, sendo dois feitos de jaspe vermelho, como indicado pela 
passagem do Livro dos Mortos acima. Para interpretarmos a presença desses amuletos em seu contexto, primeiramente devemos entender que esse fato não quer dizer que a não elite entendia a passagem do Livro dos Mortos, uma vez que nem teriam contato com as fontes textuais, mas que esse grupo social tinha acesso ao conceito e a cultura material que estava sendo produzida, circulada e usada ao seu redor.

R. Bussmann afirma que "não é a imagem individual que carrega significado, mas como as imagens estão unidas para formar um repertório visual", permitindo que amuletos sejam mais do que simples representações de conceitos formais que hoje podemos reconhecer através da cultura textual e iconográfica produzida para a elite. A não elite por ter contato limitado com essas culturas materiais estava mais propensa a reunir recursos disponíveis para se proteger e assim apropriar-se de significados e atribuir os seus próprios aos amuletos (Bussmann 2018: 9-11). Logo, interpretar os amuletos no contexto da não elite é entender que o seu significado não é inerente a eles, mas conferido por meio de práticas.

\section{Conclusão}

A interpretação do significado dos amuletos em enterramentos de não elite através da abordagem contextual revela que esses objetos são mais comuns como acompanhamento funerário de mulheres e crianças. Apesar disso, o caráter protetivo também é verificado em sepultamentos do sexo masculino por meio da presença de amuletos representando símbolos divinos, divindades e animais, porém em menor número. A utilização de amuletos nesse contexto expressa uma concepção geral associada à proteção do corpo, extremamente vulnerável durante a vida e, possivelmente, também na morte.
A predominância de amuletos associados com o sagrado e a preferência por estarem em contato com o corpo sugere que essas pessoas desejavam alguma proteção através da atribuição de amuletos como acompanhamentos funerários.

Mesmo assim, interpretações de significado podem ir mais adiante em razão do protagonismo dos amuletos em enterramentos de não elite, e até de sua ausência, algo que indica variações de crenças e práticas dentro da mesma sociedade. Esses diferentes significados podem expressar formas de proteção distintas. Mesmo fazendo parte do mesmo grupo social, essas pessoas poderiam apresentar preocupações específicas dependendo do gênero e idade, como mulheres e crianças, vulneráveis a diversas situações cotidianas, como parto e alta mortalidade infantil. Além disso, grupos menos influentes e com acesso limitado a recursos ainda possuíam agência suficiente para se apropriar de certos objetos e simbolismos mais associados com a elite e ressignificá-los a partir de interações e relações sociais que expressam uma variabilidade de crenças e simbolismos. Entender o contexto e as práticas em que esses amuletos estavam inseridos potencializa sua compreensão como acompanhamentos funerários. Dessa maneira, não devemos reforçar uma interpretação generalizante para esses objetos, mas sim fazêlo através da busca e análise de informações presentes em seu contexto.

\section{Agradecimentos}

Agradeço a FAPESP pelo apoio da fundação no financiamento da pesquisa de mestrado da qual este artigo se originou (Processo no 2018/15426-7, Fundação de Amparo à Pesquisa do Estado de São Paulo (FAPESP).

ARROYO. V. The role of amulets in cemeteries of the non-elite in Ancient Egypt. Rev. Museu Arq. Etn., 35: 69-78, 2020.

Abstract: This article expands the notion of amulets in Ancient Egypt by discussing aspects of the contextualization of these objects in non-elite cemeteries. We demonstrate contextual variability and a social diversity characterized by different practices, 
appropriations and re-significations of this material culture in burials. Our aim is to question general interpretations of amulets constructed according to textual and iconographic sources available only to the elite. Contextual analysis of data of amulets found in cemeteries from three sites, Gurob, Matmar and Lahun, was the methodology used to reflect on the different practices and beliefs regarding the non-elite.

Keywords: Amulets; Ancient Egypt; Non-elite; Funerary practices.

\section{Referências bibliográficas}

Andrews, C. 1994. Amulets of Ancient Egypt. British Museum Press, London.

Aston, D. 2009. Burial assemblages of dynasty 21-25: chronology, typology, developments. Verlag der Österreichischen Akademie der Wissenschaften, Vienna, Austria.

Baines, J.; Lacovara, P. 2002. Burial and the dead in ancient Egyptian society: Respect, formalism, neglect. Journal of Social Archaeology 2: 5-36.

Barguet, P. 1967. Le Livre des Morts des Anciens Egyptiens. Les Éditions du Cerf, Paris.

Brunton, G. 1920. Lahun I: The Treasure. Bernard Quaritch, London.

Brunton, G. 1948. Matmar. Bernard Quaritch, London.

Brunton, G.; Engelbach, R. 1927. Gurob. BSAE/ERA 10, London.

Bussmann, R. 2015. Egyptian Archaeology and Social Anthropology. Oxford Handbooks Online. Disponível em: <https://bit.ly/32w1ZST $>$. Acesso em: 27/08/2020. DOI 10.1093/ oxfordhb/9780199935413.013.24.

Cahail, K.M. 2014. In the Shadow of Osiris: Non-royal mortuary landscapes at South Abydos during the late Middle and New Kingdoms. PhD Thesis. University of Pennsylvania, Pennsylvania.

Grajetzki, W. 2010. Class and Society: Position and Possessions. In: Wendrich, W. (Ed.). Egyptian Archaeology. Blackwell Publishing, Oxford, 180-199.
Goulding, E. 2013. What did the poor take with them? An investigation into ancient egyptian eighteenth and nineteenth dynasty grave assemblages of the non-elite from Qau, Badari, Matmar and Gurob. Golden House Publications, London.

Hodder, I. 1987. The Contextual Analysis of Symbolic Meanings. In: Hodder, I. (Ed.). The Archaeology of Contextual Meanings. Cambridge University Press, Cambridge, 1-10.

Hodder, I. 1992. Theory and Practice in Archaeology. Routledge, London.

Hodder, I.; Hutson, S. 1986. Reading the Past. Cambridge University Press, Cambridge.

Humphreys, R. 2010. Matmar: Revisiting Burial Practice of the Non-Elite during the Third Intermediate Period. $\mathrm{PhD}$ Dissertation. University of Birmingham, Birmingham.

Ikram, S. 2003. Death and burial in ancient Egypt. The American University in Cairo Press, Cairo.

Janulíková, B. 2017. Non-elite mortuary variability in the Early Dynastic Memphite region. Tese de doutorado. University of Cambridge, Cambridge.

Kemp, B. 1984. In the Shadow of Texts: Archaeology in Egypt. Archaeological Review from Cambridge 3: 19-28. Disponível em: <https://bit. ly/2QuFrwn>. Acesso em: 27/08//2020.

Kemp, B. et al. 2013. Life, death and beyond in Akhenaten's Egypt: excavating the South Tombs Cemetery at Amarna. Antiquity 87: 64-78. 
O papel dos amuletos em cemitérios de não elite no Antigo Egito

R. Museu Arq. Etn., 35: 69-78, 2020.

Lemos, R. 2015. Os costumes funerários da não elite no Egito e na Núbia durante o Reino Novo: os cemitérios de Fadrus, Tell el-Amarna e Medinet el-Ghurab (XVIII-XIX dinastias). Dissertação de mestrado. Museu Nacional, Universidade Federal do Rio de Janeiro, Rio de Janeiro.

Lemos, R. 2017. Material culture and social interactions in New Kingdom non-elite cemeteries. In: Chyla, J. et al. (Eds.). Current Research in Egyptology 2016: Proceedings of the Seventeenth Annual Symposium. Oxbow, Oxford, 121-135.

Lemos, R. 2018. Materiality and cultural reproduction in non-elite cemeteries. In: Maynart, É. et al. (Eds.). Perspectives on materiality in ancient Egypt - agency, cultural reproduction and change. Archaeopress, Oxford, 24-34.

Muñoz Pérez, C. 2018. "All that glitters is not gold": the symbolism and materiality of Egyptian funerary amulets. In: Maynart, É. et al. (Eds.). Perspectives on materiality in ancient Egypt - agency, cultural reproduction and change. Archaeopress, Oxford, 64-73.
Petrie, W.M.F.; Brunton, G.; Murray, M.A. 1923. Lahun II. British School of Archaeology in Egypt; Bernard Quaritch, London.

Pinch, G. 1993. Votive offerings to Hathor. Griffith Institute, Ashmolean Museum, Oxford.

Pinch, G. 2000. Redefining Funerary Objects. In: Hawass, Z. (Ed.). Egyptology at the Dawn of the Twenty-First Century, Volume II. The American University in Cairo Press, Cairo, 443-447.

Pinch, G. 2002. Handbook of Egyptian Mythology. ABC-Clio, Santa Barbara.

Richards, J. 2005. Society and Death in Ancient Egypt: Mortuary Landscapes of the Middle Kingdom. Cambridge University Press, Cambridge.

Shaw, I. 2000. The Oxford History of Ancient Egypt. Oxford University Press, Oxford.

Stevens, A. 2006. Private religion at Amarna the material evidence. Archaeopress, Oxford.

Taylor, J. H.; Antoine, D.; Vandenbeusch, M. 2014. Ancient lives, new discoveries: eight mummies, eight stories. The British Museum Press, London. 